\title{
Personality Filters for Online News Interest and Engagement
}

\author{
Ragnhild Eg \& Arne Krumsvik \\ Department of Health Sciences, Kristiania University College, ragnhild.eg@kristiania.no, \\ arne.krumsvik@kristiania.no
}

\begin{abstract}
Our many online routines leave behind trails of data about our identities, habits, preferences and connections. These data serve as filters when we seek out information, yielding relevant results and content of interest. However, commercial and political parties can use the same data to personalize persuasive messages, and some even use psychological profiles to target individuals. With this revelation come concerns that news can be framed to appeal to individual personalities.

This study investigates the relationship between personality and news engagement among predominantly young Norwegian adults across different news angles. It addresses the Big Five personality traits as well as rational and experiential information-processing styles. The results provide support for our hypothesis on the relation between neuroticism and lowered news engagement, although the effect sizes are small. When exploring isolated news stories, we find greater differentiation among the participants, suggesting that individuals' news interest really does start at the headline.
\end{abstract}

Keywords: personality, news, engagement, targeting, personalization

\section{Introduction}

Many of our daily routines have moved from the physical to the digital world, leaving behind a wealth of information. We use the internet for shopping and entertainment, for socializing and sharing content, for searching out information and for keeping updated on current affairs, to name a few. According to a forecasting report from Cisco (2017), the aggregated data from consumers worldwide will be more than 15,000 petabytes $^{1}$ per month in 2019. Big data become big business when combined with efficient data analysis. Methods such as machine learning can uncover relations between variables and measures that the human mind may not think to explore; moreover, these methods can learn individual preferences from online data to accommodate personalized messages. This implies that any form of information can be targeted at the individual, including

Eg, R. \& Krumsvik, A. (2019). Personality filters for online news interest and engagement. Nordicom Review, 40 (Special Issue 1): 177-194. doi:10.2478/nor-2019-0021. 
commercial and political messages and even news.

In today's high-choice media environment, social media are becoming increasingly important to news distribution (Krumsvik, 2017). Facebook stands out as the most-used social media platform among news seekers, followed by Youtube and Twitter. Additionally, media providers seem to follow popular applications, adding plug-ins that facilitate content sharing on platforms such as Whatsapp, Instagram and Pinterest. Many young people use social media more than any other media (Moe \& Kleiven, 2016). In Norway, nearly 90 per cent of people below the age of 24 years use social media daily or nearly daily, and even among people up to 54 years of age the number is as high as 70 per cent (Statistisk Sentralbyrå, 2018). Social media are an important news source for younger adults (Medietilsynet, 2018), but older adults also supply their daily news intake with stories shared on social media (Sakariassen et al., 2017). Some see this as a trend that moves away from traditional news outlets, with many using media for entertainment rather than information (Elvestad et al., 2014; Ksiazek et al., 2010; Moe \& Kleiven, 2016). News interest is to a large degree shaped by individual factors, among others social media activity, emotional arousal, a sharing attitude and motives for use (Kümpel et al., 2015). In Norway, political interest has been a strong indicator of a person's inclination to seek out news (Aalberg et al., 2013). News engagement further depends on demographics (Reis et al., 2017). In some countries, only half the population can be characterized as active news seekers, with age, gender and education having been established as the best demographic predictors of news avoidance, respectively (Ksiazek et al., 2010; Moe \& Kleiven, 2016). Media researchers have highlighted concerns about the fragmentation caused by the rising number of media outlets, fearing that it may lead to increased polarization between those who actively seek out news and those who avoid it (Ksiazek et al., 2010).

Although researchers are progressing towards a wide understanding of how individual characteristics influence news habits, the roles of personality and cognitive processing remain largely unexplored for online news engagement. The growing concern that filtration of online information can narrow the scope of accessible news adds to the worries pertaining to readily available tools for distributing targeted messages down to the individual level. The risk of persuasion and other types of misinformation is considerable for online news seekers and news avoiders alike. With this work, we aim to understand the role that personality traits and cognitive styles play in our selection of news with which to engage. In so doing, we wish to shed light on the potential implications that could follow predictable and tractable news interests.

\section{News engagement and news framing}

This article explores three modes of news engagement, reading, liking and sharing, selected to represent the interaction modes that social media applications typically offer. While the modes are not mutually exclusive, they differ in their nature of interaction. Whereas reading is an isolated act, a "like" can be considered light participation in the form of a recommendation, while sharing signifies greater participation in the form of distribution (Hille \& Bakker, 2013).

It can be argued that the main affordance of a news story, independent of its distribution format, is to be read. Text communicates meaning, which requires reading. How- 
ever, online media formats offer new affordances, such as social interactions, mediated environments and even emotional exposure (Nagy \& Neff, 2015). These affordances necessitate consideration of the actions that could be spurred by interest in an online news story. Granted, people sharing news with others is no new story; we were talking and writing about current affairs long before the Internet (Hermida et al., 2012). What are new are the efficient means of sharing and the unpredictable networking effects that follow. Social media provide the means to read, share and react to news content and thereby contribute to knowledge sharing in our networks, but insights into how and when we use these means are rarely shared by media providers.

With tabloid news, and so-called fake news and clickbait, we see that much of the information available online is phrased and framed to lure readers. Some media providers have made use of alluring and misleading information for decades, even centuries, but the potential to spread messages globally has expanded through social media platforms, giving rise to the analogous expression of news going viral. Anyone can produce and publish news on social media, and the lacking quality control is one likely reason for the rise of fake news (Kim \& Dennis, 2017).

On the one hand, fake news can be any fictional report camouflaged as a true news account, ranging from satire and parody to fabricated or manipulated content (Tandoc et al., 2018). On the other hand, fake news is often born from either financial or ideological motivations and therefore seeks to engage readers through rhetorical means. Similarly, tabloid media rely on advertisers to survive, advertisement requires exposure and exposure depends on readers. One common rhetorical manoeuvre is to use leads, or forward-referencing titles, to pique the interest of readers; this can be as simple as referring to something that will be revealed in the article (Blom \& Hansen, 2015). Clickbait stories can be seen as tabloid taken to the extreme, often extending beyond leads to collect clicks from readers. Biyani and colleagues (2016) described several categories of clickbait means, among them exaggeration, teasing, confusion, improper language and graphical material. These means are in wide use, and they are effective. When examining stories from 20 popular news providers on Twitter, Potthast and colleagues (2016) discovered that they all used clickbait regularly. Similarly, Rony and colleagues (2017) found in their analysis that over 30 per cent of Facebook updates from 153 mainstream media organizations qualified as clickbait; these also received more attention in the form of likes, comments and shares. Arguably, some headlines are simply too alluring to stop us from clicking and sharing.

On a larger scale, personalized and targeted news may actually take part in shaping someone's view of the world. The internet has become unfathomably expansive. Without the aid of refined search algorithms, it would be impossible for us to navigate the digital landscape and find relevant and updated information. When we enter a query into a search engine, its algorithms are designed to crawl the search results and rank relevant websites according to a number of person-related criteria (Hannák et al., 2013), for instance source reliability, location and past searches. Web content is filtered based on everything from browser history and cookies to system preferences and account information (Hannák et al., 2013; Wills \& Tatar, 2012). News sites also filter out relevant stories and interesting content, facilitated by increasingly complex machine learning frameworks (e.g. Zheng et al., 2018). The upside is that we can quickly find the information that we are seeking; the downside is that this information is contained 
within personalized filters. Our queries return pre-selected results, meaning that our narrow glimpse into the vast digital world is not a random one but shaped for us. At the extreme, some fear that we will only have access to information that corresponds to the opinions and attitudes that we already hold, efficiently shutting out any conflicting views (Flaxman et al., 2016).

\section{Personality}

In 2017, the communication company Cambridge Analytica received worldwide attention when Hannes Grassegger and Mikael Krogerus (2017) exposed its involvement in certain political campaigns. The reporters shed light on how the company harvested and analysed data across social media platforms to derive insights that could be used in personalizing messages. With sufficient data, this type of psychographic profiling could even predict personality traits. According to Grassegger and Krogerus (2017), Cambridge Analytica's model built on research carried out by Michal Kosinski and his partners, who used Facebook likes to demonstrate how a regression model can predict gender, sexuality, political orientation and ethnicity (Kosinski et al., 2013). Later, Youyou and colleagues (2015) applied machine learning to one part of a data set containing Facebook likes and personality scores; with this, they were able to predict personality characteristics for the remaining data set based solely on Facebook activity data. With access to 100 likes, the accuracy of their model is better than chance; with 300 likes, the model can predict someone's personality scores better than a spouse or a partner. In other words, the digital footprints that we leave behind can be collected and assembled into a fairly accurate presentation of who we are, the attitudes that we hold and even our personalities.

Personality is a multi-faceted construct, typically assessed using observation or questionnaires to derive representations of the psychological patterns behind a person's thoughts, emotions and behaviours. The Big Five personality inventory is a well-known personality test that provides scores on five descriptive scales, presented in Figure 1, each representing a personality trait (Engvik \& Claussen, 2011). Its application is used for assessing five broad dimensions of personality (Schmitt et al., 2007); thus, it provides accumulated scores for an individual's own evaluation of his or her tendency to think and act according to five overall traits. As such, the Big Five approach is useful for revealing personality characteristics that may influence behaviour and attitudes in specific contexts.

The Big Five dimensions can explain individual variation in diverse contexts, for instance lifestyle habits (Paunonen, 2003). They can even indicate differential online habits. For instance, Tuten and Bosnjak (2001) uncovered a positive relationship between openness to experience and use of the web for product information and entertainment purposes, whereas neuroticism correlated negatively with all web activity. Facebook usage represents another type of online behaviour. One Australian survey study found that adult Facebook users score higher on extraversion and lower on conscientiousness than non-users; moreover, conscientiousness correlated negatively with time spent on the platform, whereas neuroticism yielded a positive correlation (Ryan \& Xenos, 2011). The authors attributed the latter correlation to a greater preference for passive engagement, as one would have with the Facebook news feed. Well-established personality inventories 
Figure 1. The five dimensions of the Big Five inventory

Openness to experience Closedness to experience
Conscientiousness
Extraversion
Emotional stability

Comment: The five dimensions of the Big Five inventory, ranging from one extreme to another. Each dimension score gives an indication of an individual's tendency to act according to his or her standing on the particular trait.

such as the Big Five have often been refined and adapted over the years, with versions being developed and standardized for different languages and tested across cultures (Schmitt et al., 2007). Shorter versions of the inventory have also emerged (Engvik \& Claussen, 2011; Rammstedt \& John, 2007), and, although they have been found to be less accurate, they provide more expedient means of evaluation. A short version of the Big Five inventory is therefore well suited when using the traits as a roadmap to explore unknown relations.

In addition to the Big Five, Tuten and Bosnjak (2001) measured a cognitive facet in their study of personality and web usage. Need for cognition is a personality trait that indicates a predilection for engaging in and enjoying activities that require effortful thinking (Perse, 1992). By including this factor, Tuten and Bosnjak (2001) discovered that participants who preferred cognitive thought tended to engage in web activities that required it (Tuten \& Bosnjak, 2001). High need for cognition is also associated with utilitarian TV watching (Perse, 1992) and can have a moderating effect on the source scepticism that follows abundant exposure to news (Tsfati \& Cappella, 2005). Need for cognition leaves one aspect untouched, namely that our decisions are not always an exercise of reason: at times we "act without thinking", as the saying goes. The manner in which we seek out, select and process information can be represented by two opposing constructs. According to cognitive-experiential self-theory, behaviour and decisions reflect compromises between rational and experiential information-processing systems (Pacini \& Epstein, 1999). Simply said, we act according to how we think and feel, and we do not rely equally on what we can surmise from instinct and what we can reason from logic. Moreover, Pacini and Epstein (1999) highlighted the distinction between engagement and ability, a distinction that separates the preference for engagement in cognitive or spontaneous activities from the actual action, the ability to make reasoned or intuitive choices. Hence, their Rational-Experiential Inventory is useful for understanding two dimensions of decision making, one ranging from rational to experiential and the other ranging from ability to engagement.

\section{A study on personality and news engagement}

Reader engagement is certainly an objective for news providers, and our digital profiles can be considered social currency in this regard. Advertisement is no longer 
targeted at demographics alone but personalized based on information that we knowingly provide social media platforms such as Facebook and unknowingly pass on to third-party companies (Cabañas et al., 2018). Being targeted as individuals, we see the need to understand better how personality relates to specific combinations of editorial and rhetorical strategies. The prospect of individualized journalism poses serious concerns about further polarization between news seekers and news avoiders and possibly between rational and intuitive information processing. We know that demographics can predict news interest, that social media behaviour can predict personality traits and that personality analyses can be used to tailor targeted messages. However, there is a research gap on how personality traits may predict news preference and engagement. The aim of this paper is to start filling this gap with a deeper understanding of what lies behind subjective news interest. We explore how rhetorical and visual mechanisms may have different appeals, and we look at the personality characteristics of users who might be more susceptible to tabloid means and consequently more vulnerable to commercial and political misinformation. Combined, personality traits and information-processing styles can shed light on news habits and preferences across genres and formats.

In addressing the relation between personality traits and news engagement, we rely on the, at times, contradictory body of work on the Big Five personality inventory and online behaviour. We put weight on findings indicating that high scores on neuroticism correlate with less web usage (Tuten \& Bosnjak, 2001) and more passive engagement on Facebook (Ryan \& Xenos, 2011), whereas openness to experience correlates positively with both Facebook usage (Ryan \& Xenos, 2011) and leisurely web usage (Tuten \& Bosnjak, 2001). From this, we hypothesize that:

H1. Participants who score high on neuroticism are less likely to engage with any type of news story than those who score low on this dimension.

H2. Participants who score high on openness to experience are more likely to engage with news stories that are entertaining or have sensational value than those who score low on this dimension.

Many decisions have already been made for us when we enter the media landscape, yet there are plenty left to be made when we seek out information. To explore how people may differ in their decisions on which news story to engage in, we apply the Rational-Experiential Inventory (Pacini \& Epstein, 1999) and compare rational ability and engagement with experiential ability and engagement. We predict that:

H3. Participants who score high on rational ability or rational engagement are more likely to engage with news stories that appeal to information processing than those who score low on these measures.

This study uses an experimental approach to investigate the relationship between personality and news engagement. With this approach, we make two assumptions that we wish to address in a set of exploratory analyses. The first assumption concerns the generalizability across age and gender, which we test for the three engagement modes. The second assumption concerns the manipulation of the news angle, which we test by looking at participants' own categorization of the stories presented. 


\section{Method}

We conducted a behavioural experiment with 180 predominantly young adults to investigate the relationships between the Big Five personality dimensions and the rationalexperiential information-processing styles and the differential engagement with news angles and presentation modes. The participants rated the likelihood of engaging with presented news stories that varied in rhetorical angle and verbal/visual presentation mode. To compare interest across news angles, we included both an experimental manipulation with tabloid and informative rhetorical angles and a subjective categorization task designed to yield descriptive labels for the different news stories. The experiment was divided into sections, with engagement and categorization tasks separated by the two short personality inventories.

\section{Participants}

We recruited our convenience sample of 180 participants from Kristiania University College. The participants' ages ranged from 18 to 71 years, whereas the gender distribution included 118 women, 61 men and 1 unspecified person. The majority of participants were recruited when visiting lectures and asking for volunteers, which explains the skewed age distribution. We can only speculate that the reason for the high female ratio is related to an overrepresentation of females at the departments that we visited. This issue is addressed further in the results and discussion section.

\section{Stimuli and material}

We collected twenty news stories from five Norwegian news sites. To ensure variety, we selected two stories for each of ten genres, ranging from finance and international affairs to lifestyle and sports. We used the titles (headlines) of the news stories and categorized each story's angle as either informative or tabloid, based on the rhetorical devices. We then formulated an alternative title for the angle that was not covered. We also collected the pictures used to illustrate the stories. Each news story was presented with the three engagement measures, read, like and share, assessed using five-point Likert scales ranging from not likely to very likely.

The experiment included a Norwegian twenty-item version of the Big Five personality characteristics (BFI-20) (Engvik \& Claussen, 2011) and the forty-item RationalExperiential Inventory (REI-40) (Pacini \& Epstein, 1999). The latter maps out the information-processing styles along two axes, rational versus experiential and ability versus engagement. Thus, the results from the inventory placed individuals in one of four categories, shedding light not only on their information-processing style but also on their behaviour and attitude. In addition to the two inventories, we included background questions on basic demographics, time spent on news, time spent on social media, most important news source and experienced importance of staying updated.

The experiments concluded with a categorization task, in which the participants were asked to choose a label for the news stories that they had encountered. The task included six options: factual, vulgar, informative, alluring, sensational and questioning. 


\section{Design}

We created two versions of the experiment to counterbalance the order of verbal presentations and verbal+visual presentations. We further divided each experiment into sections, so the BFI-20 separated the engagement task for the two presentation modes and the REI-40 created a new separation before the categorization task. For the engagement task, each section included all twenty news stories, ten with a tabloid angle and ten with an informative angle, which were fully randomized. The participants in Experiment A started with the verbal presentation mode, whereas the participants in Experiment B started with the verbal+visual presentation mode. In the latter section, a new angle on all twenty news stories was presented as verbal+visual stimuli in Experiment A and as verbal stimuli in Experiment B. Table 1 outlines all the sections for Experiments A and $\mathrm{B}$, and an overview of all the stimuli and the presentation orders can be found in Appendix A. Importantly, this division ensured that all the participants were exposed to the same stimuli and only provided engagement scores once for each stimulus. Although they encountered two angles of the same story, this happened in separate sections and with different presentation modes.

Table 1. Experimental design with a counterbalanced task order

\begin{tabular}{|c|c|c|}
\hline & Experiment A & Experiment B \\
\hline Section 1 & Information and consent & Information and consent \\
\hline Section 2 & $\begin{array}{l}\text { Demographics and news interest } \\
\text { questionnaire }\end{array}$ & $\begin{array}{l}\text { Demographics and news interest } \\
\text { questionnaire }\end{array}$ \\
\hline Section 3 & $\begin{array}{l}\text { Engagement task, } \\
\text { verbal presentation mode }\end{array}$ & $\begin{array}{l}\text { Engagement task, } \\
\text { verbal+visual presentation mode }\end{array}$ \\
\hline Section 4 & BFI-20 & BFI-20 \\
\hline Section 5 & $\begin{array}{l}\text { Engagement experiment, } \\
\text { verbal+visual presentation mode }\end{array}$ & $\begin{array}{l}\text { Engagement experiment, } \\
\text { verbal presentation mode }\end{array}$ \\
\hline Section 6 & REI-40 & REI-40 \\
\hline Section 7 & $\begin{array}{l}\text { Categorization task } \\
\text { (same stimuli as section 3) }\end{array}$ & $\begin{array}{l}\text { Categorization task } \\
\text { (same stimuli as section 5) }\end{array}$ \\
\hline
\end{tabular}

\section{Procedure}

To provide the participants with the convenience of completing the task on their own computer, the entire experiment ran on the survey platform Questback. We gave a brief introduction prior to the experiment and emphasized that participation was voluntary. Further information and details concerning research ethics and data treatment were presented on the screen. The participants were assigned to either Experiment A or Experiment $\mathrm{B}$ based on their seating location, or by other random means, and logged on using a shortened URL. For the engagement task, the participants rated the likelihood of them reading, liking and sharing the presented news stories, while they indicated the best-fitting news genre in the categorization task. The experiment duration varied between participants but rarely exceeded 20 minutes. 


\section{Results and discussion}

\section{Data treatment, controls and statistical analyses}

We applied the following statistical analyses to investigate the effects and interactions in our data set: one-way analysis of variance (ANOVA) to test main effects with one independent and several dependent measures and multivariate ANOVA tosimultaneously test several independent variables and dependent measures, controlling for multiple comparisons and allowing for interaction effects. ANOVA statistics include effect sizes, with a partial eta-squared $\left(\eta_{p}{ }^{2}\right)$ ranging from 0 to 1 , where strong effects lie above 0.64 , moderate effects above 0.25 and the recommended minimum above 0.04 (Ferguson, 2009). In the exploratory analysis, we also used bivariate Pearson correlations to test for covariation between measures.

Data from the two inventories were treated according to the presented instructions (Engvik \& Claussen, 2011; Pacini \& Epstein, 1999), yielding individual scores in the range of one to seven for the Big Five traits and in the range of one to five for the rational-experiential traits. For each experiment version, we aggregated separate dependent variables for reading, liking and sharing news stories, also according to presentation mode and news angle. The personality and engagement scores formed the basis for the main analyses. Due to a large number of missing responses, two participants were excluded from the analyses.

News interest and web habits

Taking a closer look at the news and web habits of our participants, we found that, although they rated the importance of staying updated at an average of $3.69(S D=0.95)$, they spend a daily average of 43 minutes on staying updated on news $(M=43.24$, $S D=45.17)$. Conversely, they spend close to two hours on social media ( $M=118.57$, $S D=95.65)$. The overview in Table 2 shows that 81 per cent of the participants indicated a preference for online news, including digital media and social media, whereas 19 per cent preferred more traditional news sources, such as printed news, television, radio and friends and family.

Table 2. Participants' primary news source

\begin{tabular}{llc}
\hline & News source & Frequency \\
\hline \multirow{2}{*}{ Online news: $81 \%$} & Digital media & 99 \\
& Social media & 44 \\
\hline \multirow{3}{*}{ Offline news: $19 \%$} & TV & 5 \\
& Radio & 6 \\
& Printed news & 20 \\
& Other (friends/family) & 4 \\
\hline & Total & 178 \\
\hline
\end{tabular}

\section{News engagement and experiment version}

Considering that the participants encountered the same stimuli in the two experiments, but were counterbalanced with different presentation modes, we first wanted to control whether the response patterns differed across experiment versions. We ran a one-way 
ANOVA for the three engagement modes, which yielded no main effects for reading $(F(1,177)=2.03, n s)$, liking $(F(1,177)=0.77, n s)$ or sharing $(F(1,177)=0.22, n s)$. With this finding, we carried out the remaining ANOVAs by combining the two data sets, and we included the experiment as a between-subjects factor to incorporate the individual variation in the model.

\section{News engagement and neuroticism}

To address our first hypothesis on the relationship between neuroticism and news engagement, we ran a multivariate ANOVA with the Big Five factor emotional stability and engagement scores. The analysis returned no significant results for liking $(F(1,178)=0.30, n s)$ or sharing $(F(1,178)=1.16, n s)$ but did reveal an interaction with reading $\left(F(1,178)=5.48, p=.02, \eta_{p}{ }^{2}=0.03\right)$. To explore the interaction with reading further, the participants were ranked according to their scores on emotional stability, and engagement scores were grouped for the half that scored lowest on emotional stability and the half that scored highest on emotional stability. The two groups thus contained individuals with scores that showed tendencies towards neuroticism or tendencies towards emotional stability. The average reading engagement scores in Figure 2 show that the difference between the groups is approximately 0.2 . Although this difference is small, it suggests a step away from the middle range, where the scores cluster. At best, this serves as a weak indication that Hypothesis 1 may hold and that people who score high on neuroticism are less likely to engage in news, albeit only for news reading.

Figure 2. Average reading engagement scores for individuals who tend towards either neuroticism or emotional stability

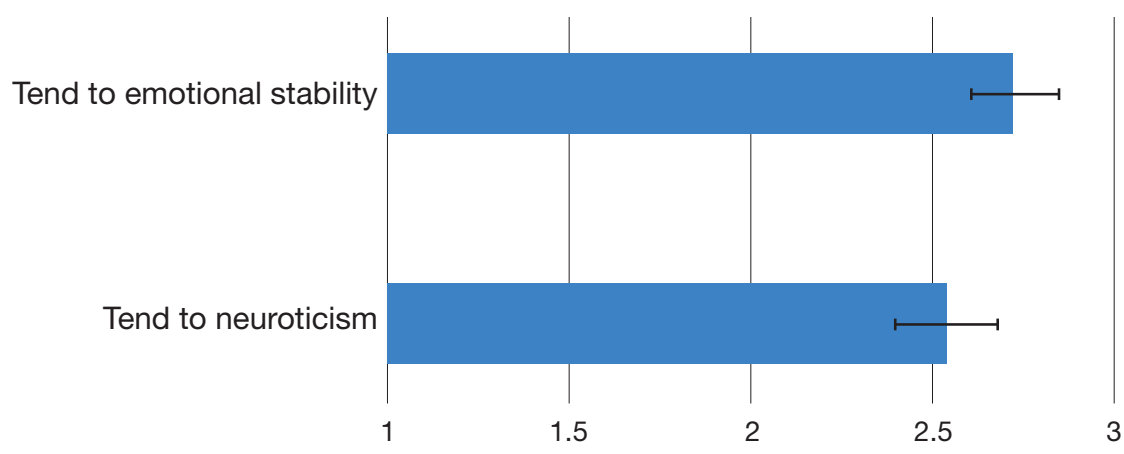

Likelihood of reading engagement

Comment: The error bars correspond to 95 per cent confidence intervals

News engagement, news angle, presentation mode and personality characteristics

Hypotheses 2 and 3 refer to the nature of the news stories, H2 centring on stories with entertaining or sensational value and $\mathrm{H} 3$ focusing on news that appeals to information processing. We carried out four multivariate ANOVAs to investigate the relationship between personality characteristics and news content. We ran separate analyses for the Big Five Inventory and the Rational-Experiential Inventory as well as separate analyses for presentation mode and news angle. All the results are summarized in Table 3. 
Personality Filters for Online News Interest and Engagement

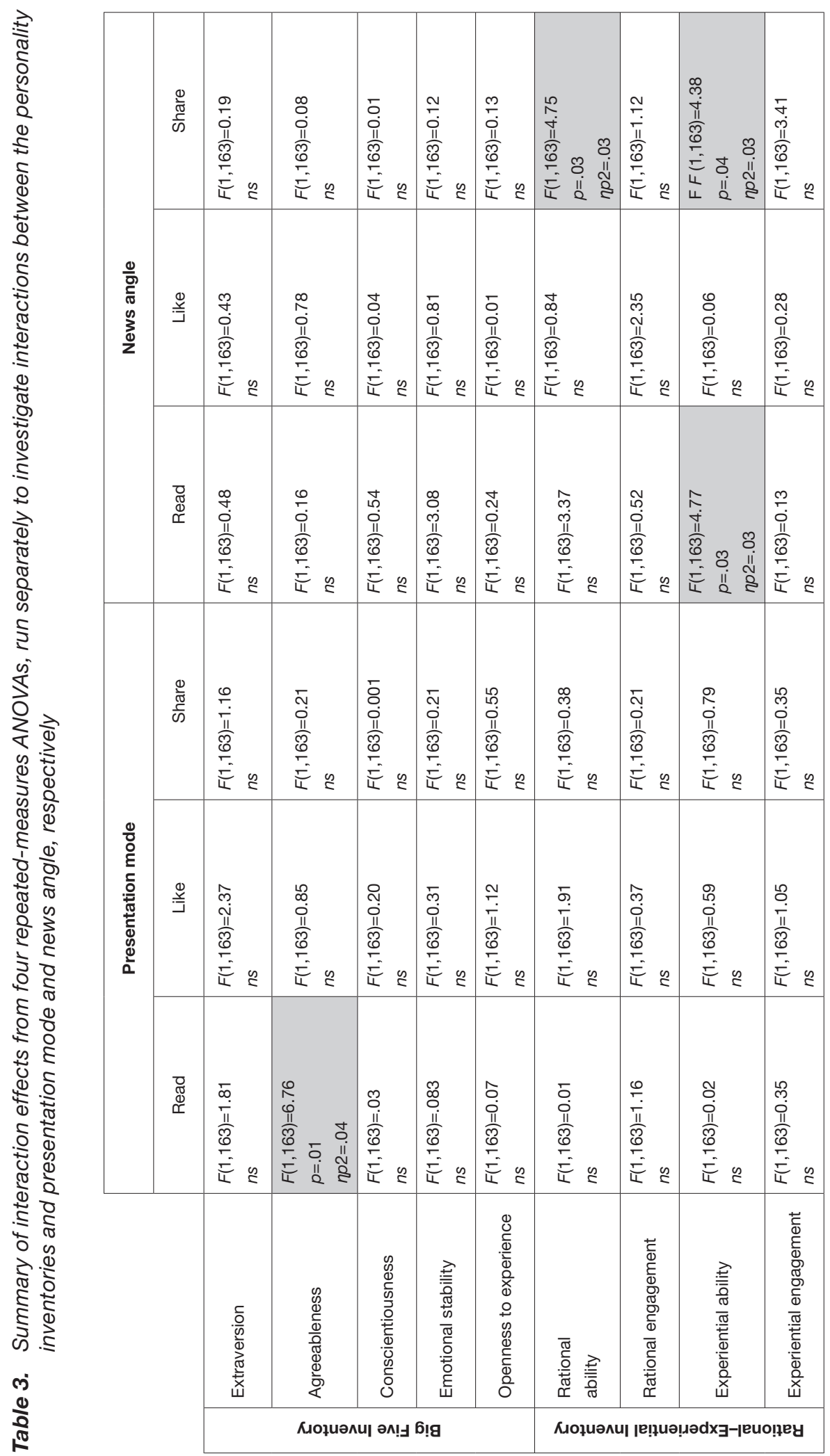


One observation made across the full data set is the low likelihood of liking and sharing the presented stories; the vast majority of responses corresponds to the lowest score. Two further observations stand out from the summary in Table 3. The first is that the majority of personality characteristics show no interaction with news engagement; evidently neither the presentation modes nor the news angles had distinct differential appeals. Consequently, we found no support for Hypothesis 2 on the relation between openness to experience and entertaining or sensational news. The second observation is that the effect sizes of the uncovered interactions are small; in fact, only one corresponds to the recommended minimum above 0.04 (Ferguson, 2009). The implication is that the significant interaction between rational ability and news angle cannot be considered relevant, lending no support to Hypothesis 3 on the suggested appeal of information processing to people who score high on rational ability or rational engagement. To explore the one interaction with effect size 0.04 , between agreeableness and presentation mode, we again ranked the participants according to their trait scores. This yielded reading likelihood responses for one group that was high on agreeableness and one group that was low. The average reading responses are presented in Figure 3, which demonstrates that the recommended minimum effect size is still too small to indicate meaningful differences.

Figure 3. Average likelihood of reading a news story presented with or without a photo for those scoring at the lower and higher ends of the agreeableness scale

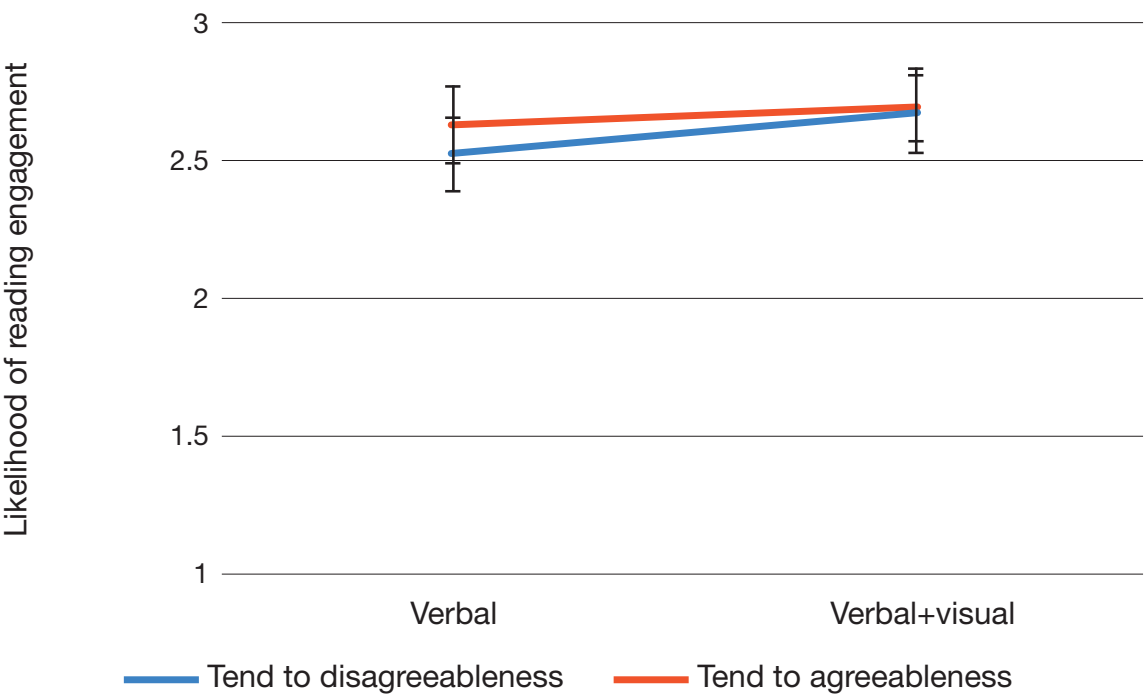

Comment: The error bars correspond to 95 per cent confidence intervals

Further exploration of news engagement, news categories and personality characteristics

In addition to addressing the three hypotheses, we also set out to explore the implications of two initial assumptions pertaining to the generalizability across age and gender and the manipulation of news angles. 
To address the first assumption, we ran multivariate ANOVAs for age and gender, with all the engagement modes as dependent measures. We based the "young adult" participant group on SSB's (2018) division and adhered to the 10-year interval for the next group, leaving a small proportion of participants for the remaining group. As seen in Table 5, neither age nor gender groups differed in their likelihood of reading the presented news. Although male participants, and the oldest age group, exhibited a slightly greater inclination towards news reading engagement, the differences are small and not statistically significant. Thus, we have not uncovered differential news habits that can be attributed to demographics, such as those observed by Reis and colleagues (2017).

Table 4. Summary of the results from two multivariate ANOVAs, run separately for age and gender groups (note that one participant did not report gender and three did not report age)

\begin{tabular}{|c|c|c|c|c|}
\hline & & Read & Like & Share \\
\hline \multirow{4}{*}{ 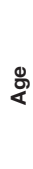 } & F-statistic & $F(2,168)=1.96, n s$ & $F(2,168)=0.22, n s$ & $F(2,168)=0.45, n s$ \\
\hline & Mean 18-24 $(n=104)$ & $M=2.64(S D=0.64)$ & $M=1.15(S D=0.33)$ & $M=1.15(S D=0.38)$ \\
\hline & Mean 25-34 $(n=49)$ & $M=2.57(S D=0.62)$ & $M=1.17(S D=0.45)$ & $M=1.14(S D=0.28)$ \\
\hline & Mean 35-71 $(n=21)$ & $M=2.86(S D=0.76)$ & $M=1.14(S D=0.26)$ & $M=1.22(S D=0.36)$ \\
\hline \multirow{3}{*}{$\begin{array}{l}\frac{1}{0} \\
\frac{0}{0} \\
0\end{array}$} & F-statistic & $F(1,168)=0.79, n s$ & $F(1,168)=0.88, p=.047$ & $F(1,168)=0.75, p=.040$ \\
\hline & Mean females $(n=114)$ & $M=2.60(S D=0.62)$ & $M=1.11(S D=0.31)$ & $M=1.12(S D=0.26)$ \\
\hline & Mean males $(n=60)$ & $M=2.70(S D=0.71)$ & $M=1.22(S D=0.43)$ & $M=1.23(S D=0.46)$ \\
\hline
\end{tabular}

Although our main analyses revealed significant relationships between personality factors and news angles, the effect sizes were small. This could imply that the assessed personality traits simply do not play a large role in the selection of news stories to read or engage in otherwise. However, the absent effects could also be indications of scores averaging out across news stories. To address our second assumption, in which the impact of the presented news angle depends fully on our experimental manipulation, we explored how personality traits relate to news engagement as judged by the participants.

We used participants' news labels, derived from the categorization task, to carry out exploratory analyses of the potential correlations between individual news stories and personality, keeping the data separate for Experiments A and B. By excluding all stories for which the agreement scores fell below the ninety-ninth percentile, we ensured that the analysis only included five news stories with a high degree of agreement, as presented in Table 5. The first three belong to Experiment A and the last two to Experiment B. With one exception, the participants categorized the informative stories as informative and the tabloid as either vulgar or alluring. Still, one of the informative stories was perceived to be alluring. 
Table 5. Five news stories selected for an exploratory analysis of the correlation between individual stories and personality characteristics, all with high agreement on the news category

\begin{tabular}{|c|c|c|c|c|}
\hline $\begin{array}{l}\text { Experimental } \\
\text { condition }\end{array}$ & $\begin{array}{l}\text { Most frequent } \\
\text { category } \\
\text { selection }\end{array}$ & $\begin{array}{l}\text { Partici- } \\
\text { pant agre- } \\
\text { ement }\end{array}$ & Norwegian version & English translation \\
\hline Crime, tabloid & Vulgar & $68.54 \%$ & 1. Avkledd og avslørt & 1. Undressed and exposed \\
\hline $\begin{array}{l}\text { Personal story, } \\
\text { informative }\end{array}$ & Alluring & $68.54 \%$ & $\begin{array}{l}\text { 2. Fant mynter for } 5,5 \text { mil- } \\
\text { lioner, får ingenting }\end{array}$ & $\begin{array}{l}\text { 2. Found coins worth } 5.5 \\
\text { million, gets nothing }\end{array}$ \\
\hline $\begin{array}{l}\text { Lifestyle, } \\
\text { informative }\end{array}$ & Informative & $77.53 \%$ & $\begin{array}{l}\text { 3. Vask baderomsvifta for } \\
\text { bedre luftkvalitet }\end{array}$ & $\begin{array}{l}\text { 3. Clean the bathroom fan } \\
\text { to improve air quality }\end{array}$ \\
\hline $\begin{array}{l}\text { Finance, } \\
\text { tabloid }\end{array}$ & Alluring & $66.67 \%$ & $\begin{array}{l}\text { 4. Koster nesten en mil- } \\
\text { lion kroner, men ingen får } \\
\text { overnatte }\end{array}$ & $\begin{array}{l}\text { 4. It costs nearly one million } \\
\text { kroner, but nobody can stay } \\
\text { overnight }\end{array}$ \\
\hline $\begin{array}{l}\text { Local politics, } \\
\text { informative }\end{array}$ & Informative & $71.11 \%$ & $\begin{array}{l}\text { 5. Nøkkelproblemer og } \\
\text { IT- systemer som feilet var } \\
\text { noen av grunnene til kaos } \\
\text { da Veireno tok over }\end{array}$ & $\begin{array}{l}\text { 5. Key troubles and failing IT } \\
\text { systems were some of the } \\
\text { reasons for the chaos that } \\
\text { came with Veireno taking } \\
\text { over }\end{array}$ \\
\hline
\end{tabular}

Considering the low engagement scores for liking and sharing, we included only reading when exploring the Pearson correlations between engagement and BFI-20 and REI-40 factors for these stories. As before, we ranked the participants according to their scores on the different personality traits, creating a division between the highest and the lowest scorers. Stories 2 and 5 were the only ones to yield significant correlations, presented in Table 7 together with the reading engagement scores for the high- and low-trait groups. As can be seen, story 2, categorized as informative, was found to be more engaging by the more extraverted participants. Story 5, also informative, scored higher in reading for participants who are more prone to rational engagement, while the participants who are more prone to experiential behaviour and information processing were less likely to engage with the same story. Keeping in mind that these are individual stories, we limit our interpretations to stating that, among a collection of twenty news stories, some are likely to appeal more than others and that the appeal could vary somewhat with personality type and information-processing style.

Table 6. Correlations between REI-40 and BFI-20 factors and news categorized by participants, along with engagement modes and likelihoods for high and low scorers

\begin{tabular}{|l|l|l|l|l|c|c|}
\hline & & Engagement & & & \multicolumn{2}{l|}{ Mean engagement scores } \\
\cline { 5 - 7 } Story & Category & mode & Correlate & Statistics & Low scorers & High scorers \\
\hline 2 & Informative & Read & Extraversion & $r(88)=.27, p=.010$ & 2.59 & 3.37 \\
\hline 5 & Informative & Read & Rational engagement & $r(87)=.37, p<.001$ & 1.58 & 2.54 \\
\hline 5 & Informative & Read & Experiential ability & $r(87)=-.43, p<.001$ & 2.42 & 1.57 \\
\hline 5 & Informative & Read & $\begin{array}{l}\text { Experiential enga- } \\
\text { gement }\end{array}$ & $r(87)=-.23, p=.036$ & 2.21 & 1.72 \\
\hline
\end{tabular}




\section{General observations}

It seems that most participants found the presented stories only somewhat engaging. One consideration is the experimental set-up, which did not permit the participants to engage with the stories beyond reading the title. Instead, they were asked to indicate their likelihood of reading, liking or sharing it, providing hypothetical engagement scores that are likely not to coincide with natural news interactions. Another consideration is the stimuli material; with twenty news stories covering ten genres, we intended to provide a representative selection that would hold some appeal to most. Intentions are not always successful, and we may have missed our target. Our young participants may have specific interests and may not be overly engaged in a wide selection of events and affairs. In turn, this could be a symptom that comes with having a world of information available at the stroke of a screen yet experiencing that world through a personalized filter. Furthermore, the threshold for taking any action beyond clicking on a story to read it seems high, indicating that the "share" and "like" buttons are not commonly applied to news. This in turn poses a challenge for news organizations that seek to involve users in this manner (Kümpel et al., 2015).

We have observed that certain personality traits can affect how we engage with news stories. The relationship between reading and emotional stability is in line with our first hypothesis, which stated that participants who score high on neuroticism are less likely to engage with news than those who tend more towards emotional stability. Nevertheless, the results only provide weak support. Openness to experience did not influence any engagement measure across the experimental conditions, offering no support for our second hypothesis on the positive relationship between this trait and entertaining or sensational news. The effect sizes were all small, for the interaction between agreeableness and presentation mode as well as for the interactions between rational/experiential ability and news angle. Hence, we did not find sufficient support for our third and last hypothesis pertaining to rational ability and engagement and the appeal of information processing.

Despite the small effect sizes, we made some interesting observations when exploring two isolated news stories. These returned greater differentiation among participants than did our aggregated variables. The informative stories were found to engage the more extraverted participants and those prone to rational engagement, while the participants who are more prone to experiential behaviour and information processing were less likely to engage. If nothing else, these exploratory findings suggest that news interest really does begin with the headline and that the interest could be mediated by personality.

The effects presented here are small, but we found them with only twenty news stories and fewer than 200 participants. With decades of data collection and hundreds of thousands of readers, news providers have what they need to construct personality profiles and make far more accurate analyses (Youyou et al., 2015).

\section{Conclusion}

The last decade has seen a rise of tailored commercial and political messages, which are no longer targeted at demographics but at individuals. Persuasion is nothing new, but, with wide access to online data, media providers can uncover novel and personal insights. These data can be obtained for almost any individual who has accepted a cookie, 
connected to someone using a third-party service or unknowingly left a digital footprint in any number of ways. Along with the insight comes the means to target individuals. Filtering mechanisms are already implemented on a great number of web services, and machine learning with semantic transformations can automate personalized communication on a large scale. Combined with a few hundred likes, we see the foundation for technology that can adapt content to personality.

Much like commercial and political persuaders, journalists aim to write stories that compel readers. When they succeed, it is likely to be due to a mix of communication skills, experience and intuition. Like any story, the angle and rhetorical means of a news story can be adapted to the individual. Technology offers the potential to run news through an engine to frame the text for each reader's preference; in other words, the way is being paved for individualized journalism. At this point, ethics may be the only barrier between balanced journalism and tailored news.

\section{Note}

1. 1 petabyte equals one million gigabytes.

\section{References}

Aalberg, T., Blekesaune, A. \& Elvestad, E. (2013). Media choice and informed democracy: Toward increasing news consumption gaps in Europe? International Journal of Press/Politics, 18(3): 281-303.

Biyani, P., Tsioutsiouliklis, K. \& Blackmer, J. (2016). "8 amazing secrets for getting more clicks": Detecting clickbaits in news streams using article informality. In Proceedings of the thirtieth AAAl conference on artificial intelligence (AAAI-16) 94-100.

Blom, J. N. \& Hansen, K. R. (2015). Click bait: Forward-reference as lure in online news headlines. Journal of Pragmatics, 76: 87-100.

Cabañas, J. G., Cuevas, A. \& Cuevas, R. (2018). Facebook use of sensitive data for advertising in Europe. ArXiv e-prints [online]. Retrieved from https://arxiv.org/abs/1802.05030 [accessed 2018, March 28].

Cisco. (2017). Cisco visual networking index: Forecast and methodology, 2016-2021 [online]. Retrieved from https://www.cisco.com/c/dam/en/us/solutions/collateral/service-provider/visual-networking-index-vni/ complete-white-paper-c11-481360.pdf [accessed 2018, March 30].

Elvestad, E., Blekesaune, A. \& Aalberg, T. (2014). The polarized news audience? A longitudinal study of news-seekers and news-avoiders in Europe. In Annual meeting of the American Political Science Association, 2014, August 28-31, Washington, D.C.

Engvik, H. \& Claussen, S. (2011). Norsk kortversjon av Big Five Inventory (BFI-20) [Norwegian short version of the Big Five Inventory (BFI-20)]. Tidsskrift for Norsk Psykologforening, 48: 869-872.

Ferguson, C. J. (2009). An effect size primer: A guide for clinicians and researchers. Professional Psychology: Research and Practice, 40(5): 532-538.

Flaxman, S., Goel, S. \& Rao, J. M. (2016). Filter bubbles, echo chambers, and online news consumption. Public Opinion Quarterly, 80: 298-320.

Grassegger, H. \& Krogerus, M. (2017, January 28). The data that turned the world upside down. Motherboard [online]. Retrieved from https://motherboard.vice.com/en_us/article/mg9vvn/how-our-likes-helpedtrump-win [accessed 2018, March 15].

Hannak, A., Sapiezynski, P., Molavi Kakhki, A., Krishnamurthy, B., Lazer, D., Mislove, A. \& Wilson, C. (2013). Measuring personalization of web search. In Proceedings of the 22nd international conference on World Wide Web (527-538).

Hermida, A., Fletcher, F., Korell, D. \& Logan, D. (2012). Share, like, recommend: Decoding the social media news consumer. Journalism Studies, 13(5-6): 815-824.

Hille, S. \& Bakker, P. (2013). I like news. Searching for the "Holy Grail" of social media: The use of Facebook by Dutch news media and their audiences. European Journal of Communication, 28(6): 663-680.

\section{Acknowledgements}

Maren Kvamme Hagen has contributed a literature review to this research. 
Kim, A. \& Dennis, A. R. (2017). Says who? How news presentation format influences perceived believability and the engagement level of social media users.Kelley School of Business Research Papers, 17-48 [online]. Retrieved from https://ssrn.com/abstract=2987866 [accessed 2017, November 17].

Kosinski, M., Stillwell, D. \& Graepel, T. (2013). Private traits and attributes are predictable from digital records of human behavior. Proceedings of the National Academy of Sciences of the United States of America, 110(15): 5802-5805.

Krumsvik, A. H. (2017). Redefining user involvement in digital news media. Journalism Practice, 12(1): 19-31.

Ksiazek, T. B., Malthouse, E. C. \& Webster, J. G. (2010). News-seekers and avoiders: Exploring patterns of total news consumption across media and the relationship to civic participation. Journal of Broadcasting \& Electronic Media, 54(4): 551-568.

Kümpel, A. S., Karnowski, V. \& Keyling, T. (2015). News sharing in social media: A review of current research on news sharing users, content, and networks. Social Media and Society, 1(2): 1-14.

Medietilsynet (2018, May 4). Sosiale medier er barn og unges viktigste nyhetskilde. Medietilsynet [online]. Retrieved from http://www.medietilsynet.no/om/aktuelt/sosiale-medier-er-barn-og-unges-viktigstenyhetskilde/ [accessed 2018, October 29].

Moe, A. \& Kleiven, H. H. (2016). Bruksmangfold. En analyse av nordmenns nyhetskonsum. TFoU-rapport 2016:7. Steinkjer: Trøndelag R\&D Institute.

Nagy, P. \& Neff, G. (2015). Imagined affordance: Reconstructing a keyword for communication theory. Social Media and Society, 1(2).

Pacini, R. \& Epstein, S. (1999). The relation of rational and experiential information processing styles to personality, basic beliefs, and the ratio-bias phenomenon. Journal of Personality and Social Psychology, 76(6): 972-987.

Paunonen, S. V. (2003). Big Five factors of personality and replicated predictions of behavior. Journal of Personality and Social Psychology, 84(2): 411-424.

Perse, E. M. (1992). Predicting attention to local television news: Need for cognition and motives for viewing. Communication Reports, 5(1): 40-49.

Potthast, M., Köpsel, S., Stein, B. \& Hagen, M. (2016). Clickbait detection. In N. Ferro et al. (eds.), Advances in information retrieval. ECIR 2016. Lecture Notes in Computer Science, vol. 9626. Cham: Springer.

Rammstedt, B. \& John, O. P. (2007). Measuring personality in one minute or less: A 10-item short version of the Big Five Inventory in English and German. Journal of Research in Personality, 41: 203-212.

Reis, J. C. S., Kwak, H., An, J., Messias, J. \& Benevenuto, F. (2017). Demographics of news sharing in the U.S. Twittersphere. In Proceedings of the 28th ACM conference on hypertext and social media (HT'17).

Rony, M. M. U., Hassan, N. \& Yousuf, M. (2017). Diving deep into clickbaits: Who use them, to what extents in which topics with what effects? In Proceedings of the 2017 IEEE/ACM international conference on advances in social networks analysis and mining (pp. 232-239) Retrieved from https://arxiv.org/ abs/1703.09400.

Ryan. T. \& Xenos, S. (2011). Who uses Facebook? An investigation into the relationship between the Big Five, shyness, narcissism, loneliness, and Facebook usage. Computers in Human Behavior, 27: 1658-1664.

Sakariassen, H., Hovden, J. F. \& Moe, H. Bruksmønstre for digitale nyheter [Patterns of use for digital news.]. Reuters Institute digital news report, Norge 2017. Bergen: Universitetet i Bergen.

Schmitt, D. P., Allik, J., McCrae, R. R. \& Benet-Martínez, V. (2007). The geographic distribution of Big Five personality traits: Patterns and profiles of human self-description across 56 nations. Journal of CrossCultural Psychology, 38(2): 173-212.

SSB. (2018). Bruk av IKT i husholdningene. 11437: Bruk av sosiale medier, etter kjønn og alder (prosent) 2011-2018 [Domestic use of ICT. 11437: Use of social media, by gender and age (per cent)]. Statistisk sentralbyrå. Retrieved from https://www.ssb.no/statbank/table/11437 [accessed 2018, October 29].

Tandoc Jr., E. C., Wei Lim, Z. \& Ling, R. (2018). Defining “fake news". Digital Journalism, 6(2): 137-153.

Tsfati, Y. \& Cappella, J. N. (2005). Why do people watch news they do not trust? The need for cognition as a moderator in the association between news media skepticism and exposure. Media Psychology, 7: 251-271.

Tuten, T. L. \& Bosnjak, M. (2001). Understanding differences in web usage: The role of need for cognition and the five factor model of personality. Social Behavior and Personality, 29(4): 391398.

Wills, C. E. \& Tatar, C. (2012). Understanding what they do with what they know. In Proceedings of the 2012 ACM workshop on Privacy in the Electronic Society (WPES '12), 13-18.

Youyou, W., Kosinski, M. \& Stillwell, D. (2015). Computer-based personality judgments are more accurate than those made by humans. Proceedings of the National Academy of Sciences of the United States of America, 112(4): 1036-1040.

Zheng, G., Zhang, F., Zheng, Z., Xiang, Y., Yuan, N. J., Xie, X., \& Li, Z. (2018). DRN: A deep reinforcement learning framework for news recommendation. In Proceedings of the 2018 World Wide Web Conference on World Wide Web, 167-176. 


\section{Appendix A}

Overview of experimental conditions and order of stimuli presentations

\begin{tabular}{|c|c|c|c|c|c|c|}
\hline & Experiment $\mathrm{A}$ & & & Experiment B & & \\
\hline $\begin{array}{l}\text { Sec- } \\
\text { tion }\end{array}$ & $\begin{array}{l}\text { Presentation } \\
\text { mode }\end{array}$ & $\begin{array}{l}\text { Rhetorical } \\
\text { angle }\end{array}$ & $\begin{array}{l}\text { Genre and story } \\
\text { number }\end{array}$ & $\begin{array}{l}\text { Presentation } \\
\text { mode }\end{array}$ & Rhetorical angle & $\begin{array}{l}\text { Genre and story } \\
\text { number }\end{array}$ \\
\hline 3 & Verbal & Tabloid & Crime 1 & Verbal+visual & Informative & Lifestyle 2 \\
\hline 3 & Verbal & Informative & Sports 2 & Verbal+visual & Tabloid & Celebrity 1 \\
\hline 3 & Verbal & Tabloid & US affairs 1 & Verbal+visual & Informative & Crime 2 \\
\hline 3 & Verbal & Informative & Lifestyle 2 & Verbal+visual & Tabloid & Personal story 1 \\
\hline 3 & Verbal & Tabloid & Accident 1 & Verbal+visual & Tabloid & Lifestyle 1 \\
\hline 3 & Verbal & Informative & Celebrity 2 & Verbal+visual & Informative & Celebrity 2 \\
\hline 3 & Verbal & Informative & Crime 2 & Verbal+visual & Tabloid & Local politics 1 \\
\hline 3 & Verbal & Informative & International 2 & Verbal+visual & Tabloid & US affairs 1 \\
\hline 3 & Verbal & Informative & Accident 2 & Verbal+visual & Tabloid & Accident 1 \\
\hline 3 & Verbal & Tabloid & Local politics 1 & Verbal+visual & Tabloid & International 1 \\
\hline 3 & Verbal & Informative & US affairs 2 & Verbal+visual & Informative & US affairs 2 \\
\hline 3 & Verbal & Informative & Local politics 2 & Verbal+visual & Tabloid & Finance 1 \\
\hline 3 & Verbal & Tabloid & International 1 & Verbal+visual & Informative & Personal story 2 \\
\hline 3 & Verbal & Informative & Finance 2 & Verbal+visual & Informative & Sports 2 \\
\hline 3 & Verbal & Tabloid & Sports 1 & Verbal+visual & Informative & Finance 2 \\
\hline 3 & Verbal & Tabloid & Celebrity 1 & Verbal+visual & Tabloid & Crime 1 \\
\hline 3 & Verbal & Tabloid & Personal story 1 & Verbal+visual & Informative & International 2 \\
\hline 3 & Verbal & Tabloid & Lifestyle 1 & Verbal+visual & Informative & Local politics 2 \\
\hline 3 & Verbal & Informative & Personal story 2 & Verbal+visual & Tabloid & Sports 1 \\
\hline 3 & Verbal & Tabloid & Finance 1 & Verbal+visual & Informative & Accident 2 \\
\hline 5 & Verbal+visual & Tabloid & Local politics 2 & Verbal & Tabloid & Crime 2 \\
\hline 5 & Verbal+visual & Informative & Finance 1 & Verbal & Informative & Crime 1 \\
\hline 5 & Verbal+visual & Tabloid & US affairs 2 & Verbal & Informative & Local politics 1 \\
\hline 5 & Verbal+visual & Informative & Accident 1 & Verbal & Informative & Personal story 1 \\
\hline 5 & Verbal+visual & Tabloid & Crime 2 & Verbal & Tabloid & International 2 \\
\hline 5 & Verbal+visual & Informative & Sports 1 & Verbal & Tabloid & Finance 2 \\
\hline 5 & Verbal+visual & Informative & Personal story 1 & Verbal & Tabloid & Accident 2 \\
\hline 5 & Verbal+visual & Informative & International 1 & Verbal & Informative & Sports 1 \\
\hline 5 & Verbal+visual & Tabloid & Celebrity 2 & Verbal & Tabloid & Local politics 2 \\
\hline 5 & Verbal+visual & Informative & Crime 1 & Verbal & Tabloid & Personal story 2 \\
\hline 5 & Verbal+visual & Informative & Lifestyle 1 & Verbal & Informative & Accident 1 \\
\hline 5 & Verbal+visual & Tabloid & Finance 2 & Verbal & Tabloid & Lifestyle 2 \\
\hline 5 & Verbal+visual & Tabloid & Accident 2 & Verbal & Informative & Lifestyle 1 \\
\hline 5 & Verbal+visual & Informative & Celebrity 1 & Verbal & Tabloid & US affairs 2 \\
\hline 5 & Verbal+visual & Tabloid & Personal story 2 & Verbal & Tabloid & Celebrity 2 \\
\hline 5 & Verbal+visual & Tabloid & Sports 2 & Verbal & Tabloid & Sports 2 \\
\hline 5 & Verbal+visual & Informative & Local politics 1 & Verbal & Informative & US affairs 1 \\
\hline 5 & Verbal+visual & Tabloid & Lifestyle 2 & Verbal & Informative & Finance 1 \\
\hline 5 & Verbal+visual & Tabloid & International 2 & Verbal & Informative & Celebrity 1 \\
\hline 5 & Verbal+visual & Informative & US affairs 1 & Verbal & Informative & International 1 \\
\hline
\end{tabular}

